\title{
Protomeliturga catimbaui sp. nov. (Hymenoptera, Andrenidae), a segunda espécie da tribo Protomeliturgini ${ }^{1}$
}

\author{
Clemens Schlindwein ${ }^{2} \&$ Jesus Santiago Moure ${ }^{3}$
}

\author{
${ }^{1}$ Contribuição número 1616 do Departamento de Zoologia, Universidade Federal do Paraná. \\ 2 Departamento de Botânica, Universidade Federal de Pernambuco. Avenida Professor Moraes Rêgo, 50670-901 Recife, \\ Pernambuco, Brasil. \\ ${ }^{3}$ Departamento de Zoologia, Universidade Federal do Paraná. Caixa Postal 19020, 81531-980 Curitiba, Paraná, Brasil. \\ Bolsista do CNPq.
}

\begin{abstract}
Protomeliturga catimbaui sp. nov. (Hymenoptera, Andrenidae), the second species of the tribe Protomeliturgini. Protomeliturga catimbaui sp. nov., from the National Park Vale do Catimbau, Buique, Pernambuco is the second species of Protomeliturgini. Protomeliturga turnerae (Ducke, 1907) was collected in flowers of Turnera ulmifolia Linnaeus, is oligolectic and very common in Northeast Brazil. The males of Protomeliturga catimbaui sp. nov. show several orange colored paintings on meso and metassoma, a shining tegument with fine punctures and sternite 7 is projected backwards in the shape of a rounded spata with lateral carina and apicolateral teeth. The bees were collected in flowers of Turneraceae (Piriqueta sidifolia (Cambess.) Urb. var. multiflora Urb.), indicating oligolecty also for this species.

KEY WORDS. Apoidea, new species, Neotropics, Panurginae, Northeast Brazil, taxonomy, Turneraceae.
\end{abstract}

RESUMO. Protomeliturga catimbaui sp. nov., do Parque Nacional Vale do Catimbau, Buique, Pernambuco é a segunda espécie de Protomeliturgini. Protomeliturga turnerae (Ducke, 1907) foi coletada em Turnera ulmifolia Linnaeus, é oligoléctica e muito comum no Nordeste do Brasil. Os machos de Protomeliturga catimbaui sp. nov. apresentam diversos desenhos alaranjadas no meso e no metassoma, tegumento brilhante com pontuação fina e o sétimo esterno projetado para trás em forma de espata arredondada com carenas laterais e dentes látero-apicais. As abelhas foram coletadas em flores de Turneraceae (Piriqueta sidifolia (Cambess.) Urb. var. multiflora Urb.), indicando oligolectia também para esta espécie.

PALAVRAS CHAVE. Apoidea, espécie nova, neotropical, Panurginae, Nordeste do Brasil, taxonomia, Turneraceae.

Panurginae foi dividida em seis tribos por MiCHENER (2000). Rozen \& Ascher (in ROzEn 2003), recentemente, acrescentaram a tribo monotípica Nolanomelissini, baseada em Nolanomelissa toroi Rozen, 2003 do sul do Atacama, Chile. Outra tribo monotípica da subfamília é Protomeliturgini Ruz, 1991, com Protomeliturga turnerae (Ducke 1907), restrita ao Nordeste do Brasil e oligolética em flores do gênero Turnera Linnaeus (Turneraceae) (DucKe 1907: 77, 1912, Ruz 1991, Medeiros \& Schlindwein 2003, SCHLINDWEIN 2003, 2004). Esta tribo foi proposta por Ruz (1991) e mantida por Michener (2000). Fêmeas e machos de P. turnerae visitam preferencialmente flores de Turnera subulata Smith (Medeiros \& Schlindwein 2003).

Aqui é descrita a segunda espécie do gênero. Os machos foram coletados patrulhando flores de Piriqueta sidifolia (Cambess.) Urb. var. multiflora Urb. (Turneraceae).

As medidas foram feitas com ocular micrométrica em microscópio estereoscópico Zeiss Stemi SV8. O comprimento dos pêlos é aproximado, medido com aumento de 50x. Os intervalos entre os pontos estão indicados pelo número de "diâmetros de ponto" que os separam, assim um intervalo de dois diâmetros é indicado com $2 \mathrm{dp}$. Outras abreviaturas do texto são: T - Tergo; E - Esterno.

\section{Protomeliturga catimbaui sp. nov.}

Holótipo, macho. Brasil, Pernambuco: Buique (Vale de Catimbau), 12.IV.2003, C. Schlindwein leg.; UFPE 14366, depositado na Coleção de Entomologia Pe. J.S. Moure, Departamento de Zoologia, Universidade Federal do Paraná, Curitiba (DZUP). Parátipos com os mesmos dados do holótipo, 2 machos, UFPE 14371 e UFPE 14368 (sem abdome) depositados na Coleção de Entomologia da Universidade Federal de Pernambuco, Recife. 

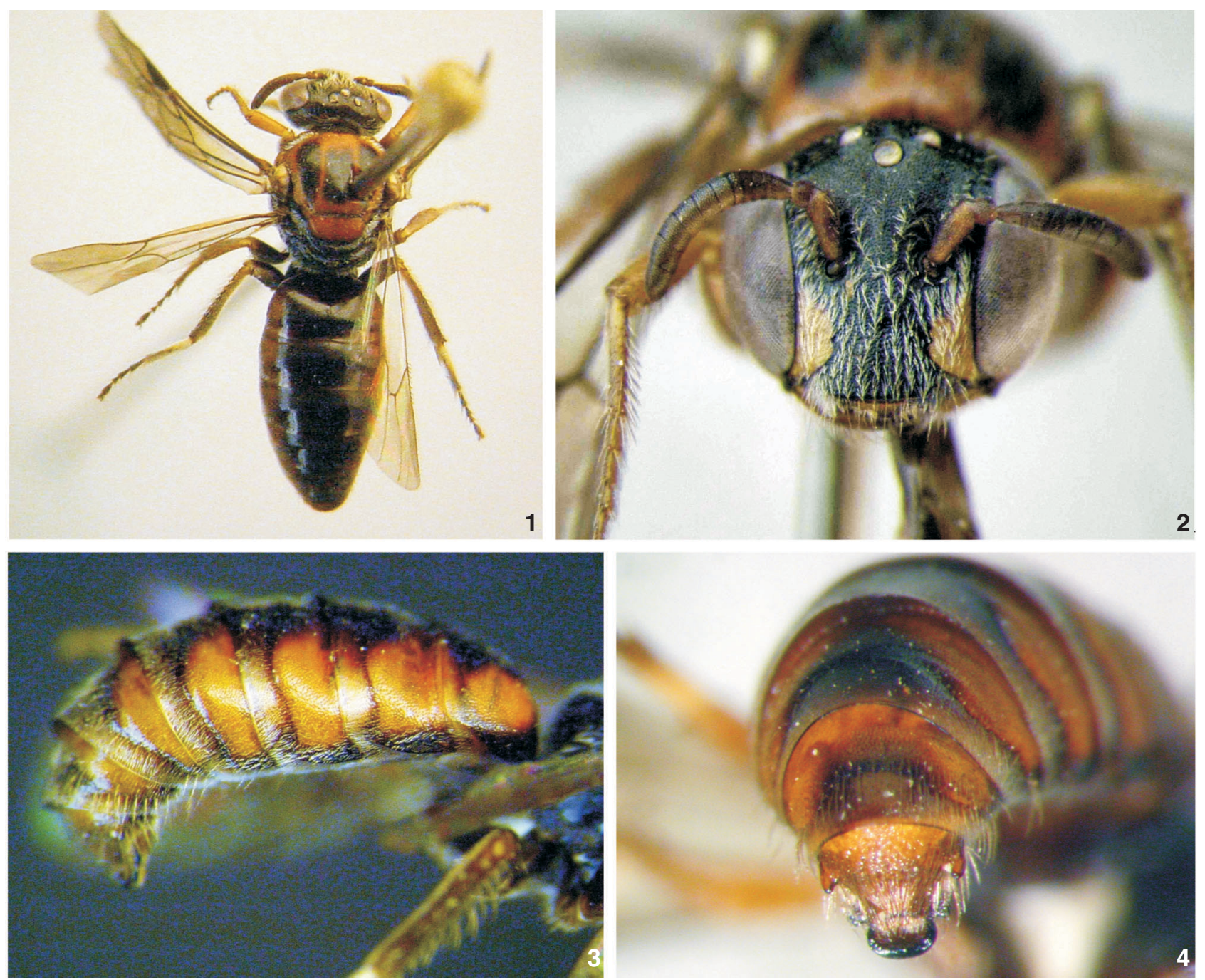

Figuras 1-4. Protomeliturga catimbaui, macho: (1) vista dorsal; (2) vista frontal da cabeça; (3) vista lateral do metassoma; (4) últimos tergos e parte do último esterno.

Diagnose. Tegumento brilhante com pontuação delicada, e diversos desenhos alaranjados (Figs 1, 3 e 4); artículos três e quatro dos palpos labiais curtos, rudimentares, formando um ângulo reto com os basais; as faixas marginais dos tergos com pilosidade bastante esparsa, sem formar faixas marginais, apenas com alguns pêlos nos flancos muito separados, sem cobrir o tegumento; flagelo mais curto do que o comprimento da face: tíbias posteriores com uma carena ao longo do bordo posterior, um pouco deformada pela grossa pontuação pilígera; T7 com dentes laterais; E7 em forma de espata arredondada, com carenas laterais e dentes látero-apicais.

Comprimento $6,5 \mathrm{~mm}$; comprimento da asa anterior 5,2 $\mathrm{mm}$, largura da cabeça $1,9 \mathrm{~mm}$.

Cores. Tegumento preto sem desenhos no clípeo; com manchas amarelas paroculares inferiores chegando quase até o nível da tangente inferior dos alvéolos antenais (Fig. 2); escapo e pedicelo amarelentos; flagelo amarelento no lado superior, marrom escuro no lado inferior; mandíbula amarela nos dois terços basais; labro com mancha amarela em " $\mathrm{T}$ "; manchas amarelas na tégula e no esclerito basal da asa; manchas alaranjadas no mesoscuto em forma de duas estrias finas centrais e duas estrias laterais, unidas anterior e posteriormente; escutelo e axilas alaranjados (Fig. 1); mesopleuras na parte anterior alaranjadas, na parte posterior e no metanoto e propódeo pretos; os lados dos tergos metassomais alaranjadas (Figs 3 e 4); as pernas alaranjadas e com uma pequena mancha na base das tíbias anteriores, médias e posteriores; uma estria amarela ao longo dos basitarsos posteriores; asas muito fracamente fuscas.

Revista Brasileira de Zoologia 22 (4): 833-835, dezembro 2005 
Pontuação evidente na cabeça, os intervalos entre os pontos 1 até $1,5 \mathrm{dp}$; intervalos no vértice um pouco maiores (cerca de $2 \mathrm{dp}$ ), brilhantes; nas genas $2 \mathrm{dp}$, lisos; mesoscuto com pontuação mais fina do que no vértice, intervalos maiores do que 2 $\mathrm{dp}$, brilhantes; no metanoto um pouco mais esparsa do que no mesoscuto e com pontos menores; no escutelo semelhante a do mesoscuto; nos mesepisternos os pontos parecidos aos do mesoscuto; na área basal do propódeo pontos mais grossos e densos (1 dp); nos tergos relativamente mais densa e forte nas áreas basais, na marginal muito fina e muito esparsa; pontuação progressivamente mais notável a medida que se aproxima do último tergo; T1 com margem posterior quase inteiramente lisa; pontuação nos esternos com intervalos de 1-1,5 dp e alguns pontos maiores intercalados, mais esparsos do que o restante; a pontuação aumenta em densidade em direção ao último esterno, neste mais densa e mais grossa.

Pilosidade pouco desenvolvida; pêlos relativamente longos no clípeo e na área supraclipeal (Fig. 2); pêlos plumosos, curtos e densos por trás das áreas elevadas pronotais; pilosidade escassa no mesoscuto, escutelo e metassoma (Fig. 1, 3); faixas apicais dos tergos com pilosidade fraca lateral e quase nula na parte média; esternos com pilosidade escassa, embora se note fracas faixas marginais.

Forma e proporções. Distâncias interorbitais: superior $1,12 \mathrm{~mm}$, inferior $0,96 \mathrm{~mm}$; interocelar $0,3 \mathrm{~mm}$; ocelorbital $0,28 \mathrm{~mm}$; diâmetro do ocelo médio $0,2 \mathrm{~mm}$; comprimento da cabeça 1,4 mm; comprimento do olho 1,04 $\mathrm{mm}$; largura do olho 0,62 mm; distância interalveolar 0,16 mm; alvéolo-orbital $0,18 \mathrm{~mm}$; diâmetro do alvéolo 0,12 $\mathrm{mm}$; fóvea facial estreita, alargada para cima, comprimento $0,6 \mathrm{~mm}$, largura $0,3 \mathrm{~mm}$; comprimento e diâmetro do escapo $0,34 \mathrm{~mm}$ e $0,16 \mathrm{~mm}$; do pedicelo $0,12 \mathrm{~mm}$ e $0,13 \mathrm{~mm}$; flagelo levemente alargado no meio, comprimento do flagelo $1,58 \mathrm{~mm}$; o ápice do labro fracamente emarginado, hámulos 7; fêmur médio arredondado, comprimento $0,96 \mathrm{~mm}$; fêmur posterior $1,08 \mathrm{~mm}$; tíbia posterior 1,38 $\mathrm{mm}$; área basal do propódeo sem carenas, apenas pontuada e com um sulco a cada lado; T2 e T3 com uma pequena depressão lateral, decrescendo no terceiro e cada um com pequeno sulco lateral; com uma carena longitudinal lateral do T2 ao T5; T7 com um dente a cada lado; E7 projetado para trás em forma de espata arredondada, com carenas laterais convergentes para o ápice e com um dente a cada lado (Fig. 4).

Comentário. Os machos de P. catimbaui assemelham-se a $P$. turnerae pela forma e proporção dos palpos labiais, tíbias posteriores com carena no bordo posterior e pterostigma com os lados divergentes; distinguem-se facilmente pela coloração alaranjada do meso e metassoma, pilosidade pouco desenvolvida, tegumento brilhante com pontuação fina e pelo menor tamanho. Em P. turnerae o T7 apresente um forte dente em cada lado, em $P$. catimbaui os dentes são mais aguçados; o E7 apresenta dois dentes e carenas convergentes para o ápice sem formar o arco típico de $P$. turnerae. Os machos patrulharam flores de Piriqueta sidifolia (Cambess.) Urb. var. multiflora Urb. (Turneraceae), indicando oligolectia como em $P$. turnerae.

Etimologia. O nome da espécie refere-se ao local onde os indivíduos foram encontrados.

\section{AGRADECIMENTOS}

Ao IBAMA pela licença de coleta no Parque Nacional Vale do Catimbau. A Artur Maia e Airton Carvalho pela ajuda nas fotografias, a Dra. Danúncia Urban (UFPR) pela revisão do manuscrito e Dra. Maria Mercedes Arbo (IBONE, Corrientes, Argentina) pela identificação de Piriqueta sidifolia.

\section{REFERÊNCIAS BIBLIOGRÁFICAS}

Ducke, A. 1907. Contribution à la connaissance de la faune hyménoptérologique du Nort-Est du Brèsil. I. Revue d'Entomologie, Caen, 26: 73-96.

Ducke, A. 1912. Die natürlichen Bienengenera Südamerikas. Zoologische Jahrbücher, Abteilung für Systematik, Geographie und Biologie der Tiere, Jena, 34: 51-116.

Medeiros, P.C.R. \& C. Schlindwein. 2003. Territórios de machos, acasalamento, distribuição e relação com plantas em Protomeliturga turnerae (Ducke, 1907) (Hymenoptera, Andrenidae). Revista Brasileira de Entomologia, Curitiba, 47 (4): 589-596.

Michener, C.D. 2000. The bees of the world. The Johns Hopkins University Press, Baltimore, London. 913p.

Rozen JR., J. G. 2003. A new tribe, genus, and species of South American parnugine bee (Andrenidae, Panurginae), olgolectic on Nolana (Nolanaceae), p. 93-108. In: G.A.R. Melo \& I. Alves-dos-Santos (Eds). Apoidea Neotropica: homenagem aos 90 Anos de Jesus Santiago Moure. Criciúma Editora UNESC, 320p.

Ruz, L. 1991. Classification and phylogenetic relationships of the panurgine bees: The Calliopsini and allies (Hymenoptera: Andrenidae). University of Kansas Science Bulletin, Lawrence, 54 (7): 209-256.

SchlindweIn, C. 2003. Panurginae (Hymenoptera, Andrenidae) in northeastern Brazil, p. 217-222. In: G.A.R. Melo \& I. Alves-DosSANTOS (Eds). Apoidea Neotropica: homenagem aos 90 Anos de Jesus Santiago Moure. Criciúma, Editora UNESC, 320p.

Schlindwein, C. 2004. Are oligolectic bees always the most effective pollinators? p. 231-240. In: F.B. MAGALHÃES \& J.O.P. Pereira (Eds). Solitary bees - conservation, rearing and management for pollination. Fortaleza, Imprensa Universitária, 285p.

Recebido em 01.III.2005; aceito em 17.IX.2005. 